\title{
Evolución del sistema institucional como parámetro de autogobierno. En particular, el entramado organizativo de Castilla y León
}

\author{
Luis Ángel Ballesteros Moffa \\ Profesor Titular de Derecho Administrativo \\ Universidad de León \\ Luis.ballesteros@unileon.es
}

\begin{abstract}
Resumen
Junto al nivel competencial reconocido y consolidado por una financiación adecuada, seguramente sea el entramado institucional al servicio del autogobierno de una Comunidad Autónoma la variable más clarificadora del grado y calidad de su autonomía política. Las tres reformas operadas sobre el Estatuto de Autonomía de Castilla y León, la última en virtud de la Ley Orgánica 14/2007, de 30 de noviembre, han encauzado una notable ampliación del marco competencial e institucional de la Comunidad, aportando a la vez desde esta parte del Estado su particular contribución al modelo territorial. El presente trabajo pretende analizar la realidad institucional y organizativa de Castilla y León, desde la óptica de la última reforma estatutaria, pero sin olvidar el contexto histórico en que la misma se ha gestado y arraigado.
\end{abstract}

Palabras clave Reformas institucionales, modelo territorial del Estado, descentralización, sistema institucional, Castilla y León.

\section{Evolution of the institutional system as a self-government parameter. In particular, the organizational framework in Castilla and Leon}

\begin{abstract}
Along with recognized competence level and strengthened by adequate funding, it is probably the institutional framework in the service of an autonomous self-government of the variable most clarifying the extent and quality of their political autonomy. The three reforms operated on the Statute of Autonomy of Castilla y León, the last under the Organic Law 14/2007 of November 30th, have channeled a significant extension of powers and institutional framework of the Community, contributing to the time since this part of the State of its particular contribution to the territorial model. This paper analyzes the institutional and organizational realities of Castilla y Leon, from the perspective of the last statutory reform, but without forgetting the historical context in which it has gestated and rooted.
\end{abstract}

Keywords

Institutional, regional model of the state, decentralization, institutional system, Castilla and Leon. 


\section{LA CONFIGURACIÓN DEL MODELO TERRITORIAL DEL ESTADO}

Con la aprobación de los últimos Estatutos de Autonomía, entre ellos el de CastiIla y León mediante la Ley Orgánica 4/1983, de 25 de febrero, ${ }^{1}$ culminó la primera etapa en la gestación del Estado autonómico o Estado de las Autonomías, cuyo punto de arranque y verdadero motor del proceso se localizaban en el art. 2, Título VIII y disposiciones adicional primera y transitorias primera a séptima de la Constitución de 1978. En el ínterin serían necesarios numerosos esfuerzos por ordenar y racionalizar este complejo proceso, lastrado desde el primer momento por la indeterminación constitucional, y en el que hubo de mediar el propio legislador (proyecto de la LOAPA purgado por la STC 76/1983, de 5 de agosto, en la Ley del Proceso Autonómico de 14 de octubre de 1983), a partir del Informe de la Comisión de Expertos sobre Autonomía presidida por Eduardo García de Enterría, de mayo de 1981, y los Acuerdos Autonómicos de 31 de julio de 1981 entre la UCD y el PSOE.

La decidida apuesta del constituyente por el principio de descentralización, no sólo haciendo posible la proyección territorial de los clásicos poderes del Estado sobre unas nuevas colectividades territoriales, sino también reconociendo la autonomía real de las Entidades Locales (en el caso de Castilla y León, recuérdese el Acuerdo de Pacto Local de noviembre de 2005 como segunda descentralización superpuesta a la estatal culminada en 1999), ${ }^{2}$ insufló al sistema de los resortes necesarios para superar la espontaneidad e improvisación de los primeros momentos, generalizándose a la postre un modelo de autonomía política prácticamente desconocido en nuestro Derecho patrio. ${ }^{3}$

Si exceptuamos el efímero episodio federal de 1873 bajo la presidencia de Pi y Margall con un proyecto de Constitución federalista y liberal que contemplaba la Nación española estructurada en diecisiete Estados (incluidos Cuba y Puerto Rico), o las diversas entidades subestatales reconocidas en la España constitucional desde una dimensión geográfico-administrativa, los precedentes se reducen prácticamente a la experiencia regionalista de la II República, junto al fenómeno preautonómico como antecedente inmediato del Estado compuesto constitucional.

La Constitución de 1978 en su disposición transitoria segunda se hace eco de este primer precedente al referirse a aquellos "territorios que en el pasado hubiesen plebiscitado afirmativamente proyectos de Estatuto de Autonomía” y contaran a la vez con regímenes provisionales de autonomía, los cuales podían acceder inmediatamente al máximo techo competencial sin necesidad de seguir todo el iter procedi-

$1 \quad$ V.AA. (Dir.: Rivero Ysern, E.): Comentarios al Estatuto de Autonomía de la Comunidad Autónoma de Castilla y León, IEAL, Madrid, 1985.

2 Véanse Martínez López-Muñiz, J. L. (Coord.): Descentralización y Administración Local, Universidad de Valladolid, Valladolid, 1992; VV.AA. (Coord.: Sosa Wagner, F.): Pacto local, Revista Jurídica de Castilla y León, núm. extraordinario, 2006; y Parada Vázquez, R.: “La segunda descentralización: del Estado autonómico al municipal”, Revista de Administración Pública, núm.172, 2007, págs. 9 a 77.

3 VV.AA.: La Constitución de 1978 y las Comunidades Autónomas, CEPC, Madrid, 2003. 
mental exigido por el art. 151. Serían suficientes a este fin un acuerdo por mayoría absoluta de los órganos preautonómicos colegiados superiores, su comunicación al Gobierno, y ulterior elaboración del Estatuto conforme al art. 151.2, donde el referéndum exigido tan sólo precisa mayoría simple de los votos válidamente emitidos. Aunque de esta vía privilegiada se beneficiaron Cataluña, País Vasco y Galicia por cumplir históricamente con los citados requisitos, en puridad, de todas las Regiones que bajo el convulso período de la Constitución republicana de 1931 reivindicaron su autonomía, fue el Estatuto catalán de 1932 el que alcanzó verdadero recorrido (el vasco y gallego no lograron aprobarse hasta iniciada la Guerra Civil); dotándose incluso la Generalidad de Cataluña por Decreto de abril de 1931, en tanto no se aprobara el Estatuto, de un Consejo o Gobierno provisional, una Diputación provisional con representantes de los Municipios, y unos Comisarios a modo de delegados del Consejo.

Mayor alcance territorial tuvo el fenómeno preautonómico como fórmulas de tránsito postuladas fundamentalmente desde las élites políticas de los territorios periféricos. ${ }^{4}$ Restablecida provisionalmente la Generalidad catalana y creado el Consejo General vasco por los Reales Decretos-Leyes 41/1977, de 29 de septiembre y 1/1978, de 4 de enero, respectivamente, hasta trece Preautonomías se pusieron en funcionamiento a través del mismo instrumento normativo de urgencia, prefigurando en buena medida el futuro mapa autonómico, a excepción de Madrid y Navarra -no acogidas a régimen preautonómico-, o del supuesto particular de Santander y Logroño. Precisamente fueron estas dos últimas Provincias periféricas del viejo Reino de CastiIla las que, a pesar de formar parte inicialmente del Ente preautonómico de Castilla y León conforme al Real Decreto-Ley 20/1978, de 13 de junio, acabaron erigiéndose en sendas Comunidades Autónomas uniprovinciales (Cantabria y La Rioja), a diferencia de León y Segovia donde su también problemática inclusión entre las once Provincias de la institución preautonómica no terminó cuajando en una autonomía separada.

Con estos antecedentes, la Constitución vigente diseña un Estado descentralizado de características absolutamente peculiares y diversas al resto de Estados compuestos del escenario internacional. Su difícil incardinación en alguno de los conocidos modelos territoriales de Estado regional (donde se parte de la unidad para reconocer la autonomía de los territorios), Estado federal (a partir de la diversidad territorial se promueve la integración en una federación) e incluso confederal (unión política de Estados soberanos), revela nuestra forma de organización territorial como un modelo suigeneris, forjado a partir de elementos heterogéneos, cuya singularidad se encuentra además sometida a constante revisión. Si los específicos caracteres propios de su inicial diseño y gestación diferenciaron al Estado de las Autonomías de otros Estados de nuestro entorno con formas de distribución territorial del poder típicamente regionales (Italia, Portugal) o federales (Alemania, Austria, Suiza), la deriva del proceso autonómico hacia fórmulas de autogobierno cada vez más acusadas no ha hecho más que enfatizar esa originalidad y eclecticismo, en una suerte de deba-

4 Funes Martínez, M.: Las preautonomías regionales en España, Caja de Ahorros de Murcia, Murcia, 1984. 
te territorial perennemente abierto o transitorio. 5 Junto a las notas vertebradoras de unidad, autonomía y solidaridad solemnemente consagradas en el art. 2 de la Norma Fundamental, puede afirmarse sin ambages que ha sido el principio dispositivo o de voluntariedad el verdadero árbitro en la configuración de nuestra organización territorial. ${ }^{6}$

Principio dispositivo presente en la propia formación de las Comunidades Autónomas, al no venir enumeradas o impuestas por el texto constitucional, sino derivarse de la iniciativa de las Provincias y demás territorios a partir de las distintas vías y momentos de acceso a la autonomía reconocidos en el mismo. Sucintamente, a través de la vía ordinaria o lenta de los arts. 143 y siguientes, como procedimiento más sencillo de iniciativa autonómica y aprobación del Estatuto, no vinculado a ninguna forma de consulta popular, pero por el que tan sólo podía asumirse el grupo de competencias del art. 148, al menos hasta que transcurriesen los cinco años de su apartado 2; o por la vía especial o rápida del art. 151, en cuanto sistema más riguroso para el acceso a la autonomía y aprobación del Estatuto, pero que como contrapartida permitía obtener el máximo nivel competencial desde un principio. Mientras por la primera se constituyeron la mayoría de las Comunidades Autónomas, en un proceso de autonomía gradual, por la segunda, junto a las Comunidades históricas beneficiadas por la ya comentada disposición transitoria segunda, accedió Andalucía. Al margen quedaron la Comunidad Valenciana y Canarias, con plena autonomía ab initio en virtud de sendas Leyes Orgánicas de transferencias ex art. 150.2 (11/1982 y 12/1982, ambas del 10 de agosto), además de los supuestos extraordinarios de la Comunidad Foral de Navarra (disposición adicional primera), ${ }^{7}$ y de las Ciudades Autónomas de Ceuta y Melilla [art. 144.b) y disposición transitoria quinta].

Principio dispositivo presente también pues en el reparto competencial, desde el momento en que no se optó por una participación igualitaria en las competencias autonómicas, sino que, vinculado al concreto procedimiento, se permitió al menos de inicio una distribución competencial asimétrica, que no ha resistido la lógica federal. Competencias autonómicas, por otra parte, no claramente deslindadas de las estatales, pues sin perjuicio de determinados criterios constitucionales, su concreción definitiva ha quedado al albur de cada Estatuto de autonomía, sus ulteriores reformas, la utilización de determinadas técnicas de transferencia o delegación de competencias estatales, o de las especiales circunstancias presentes en determinados territorios como los forales.

5 Duchacek: Comparative Federalism, University Press of America, Lanham, 1987; Watts, R., Sistemas federales comparados, trad. y estudio introductorio por Seijas Villadangos, E., Marcial Pons, Madrid, 2006; Seijas Villadangos, E.: “Organización territorial del Estado y Castilla y León”, en VV.AA. (Dir.: Sáez Hidalgo, I.): Derecho Público de Castilla y León, Lex Nova, Valladolid, 2008, págs. 39 a 61.

6 Fossas Espadaler, E.: El principio dispositivo en el Estado autonómico, Marcial Pons, Madrid, 2007.

7 Tudela Aranda, J.: “La Disposición Adicional Primera de la Constitución y los nuevos Estatutos 84 de Autonomía. La historia como la legitimación de la autonomía”, Revista de Administración Pública, núm. 
Además, y sin ánimo de agotar todos los rasgos definitorios, la brecha entre ciudadanía y proceso autonómico se ha erigido en otra de las notas sobresalientes de nuestro modelo, toda vez que la reducción en la práctica de los trámites de mayor contenido democrático en los diversos procesos de gestación y reforma ha llegado a cuestionar el mismo respaldo popular del Estado autonómico (Parada Vázquez). ${ }^{8}$ Ténganse en cuenta, en este sentido, la aprobación de los regímenes preautonómicos por Reales Decretos-Leyes; la excepción parcial por la disposición transitoria segunda de la vía del art. 151 como la única que exigía un reconocimiento explícito del cuerpo electoral, y por la cual tan sólo Andalucía accedió a la autonomía, con la salvedad de que en el caso de Almería la exigencia del refrendo popular por mayoría absoluta de la iniciativa autonómica fue suplida por determinadas Leyes Orgánicas ad hoc (Ley Orgánica 12/1980, de 16 de diciembre, de modificación de la Ley Orgánica 2/1980, de 18 de enero, sobre las distintas modalidades de referéndum; y Ley Orgánica 13/1980, de 16 de diciembre); o la mera mayoría simple requerida para los referenda de aprobación o reforma estatutaria, en aquellos casos en que se precisan, de forma que por ejemplo el Estatuto gallego fue aprobado con el 14 por ciento de votos positivos en relación a todo el cuerpo electoral de las Provincias gallegas, o el Estatuto de Cataluña reformado en el año 2006 con el 36 por ciento del censo catalán.

La Comunidad de Castilla y León, en concreto, accedió a la autonomía y aprobó su Estatuto de febrero de 1983 con arreglo a los requisitos y procedimiento previstos en los arts. 143 y siguientes, al margen de cualquier consulta popular, quedando sometida al plazo mínimo de cinco años del art. 148.2 para la ampliación competencial en el marco del art. 149. Su proceso de gestación tuvo comienzo con la formalización de la iniciativa por el Consejo General del Ente preautonómico (disposición transitoria primera), de la que se desmarcarían Santander y Logroño, y ulterior ratificación de la misma por las Corporaciones Locales de cada una de las Provincias, con las vicisitudes referidas en los casos de León y Segovia [en esta última incluso fue necesario acudir al mecanismo excepcional del art. 144.c) sustituyendo la iniciativa local en virtud de la Ley Orgánica 5/1983, de 1 de marzo]. Asentada definitivamente en el puzzle autonómico, comenzaría la andadura de la Comunidad, donde hasta el día de hoy hasta tres reformas estatutarias han marcado los puntos de inflexión, dentro de un contexto general de consolidación y profundización de la realidad autonómica. ${ }^{9}$

Tras el fracaso de una primera propuesta de reforma, el Estatuto de Castilla y León fue modificado por vez primera en virtud de la Ley Orgánica 11/1994, de 24 de marzo, como consecuencia de un proceso general de ampliación de competencias, una vez superado con creces el plazo del art. 148.2 (Acuerdos Autonómicos de 28

8 Parada Vázquez, R.: Derecho Administrativo Il. Organización y empleo público, Marcial Pons, Madrid, 2007.

9 VV.AA. (Coord.: García Roca, J.): Derecho Público de Castilla y León, Universidad de Valladolid, 1999; VV.AA.: La Reforma de los Estatutos de Autonomía, Revista Jurídica de Castilla y León, 2003; Sanz Pérez, A. L.: La reforma de los Estatutos de Autonomía, Thomson-Aranzadi, Navarra, 2006; Bilbao Ubillos, J. M. a: "Iniciativa autonómica y sucesivas reformas del Estatuto de Autonomía de Castilla y León”, en VV.AA. (Dir.: Sáez Hidalgo, I.): Derecho Público de Castilla y León, Lex Nova, Valladolid, 2008, págs. 63 a 124. 
de febrero de 1992 entre el PSOE y el PP). Si fruto del primero de los compromisos contenidos en los Acuerdos fue aprobada la Ley Orgánica 9/1992, de 23 de diciembre, de Transferencia de Competencias de Titularidad Estatal a las diez Comunidades Autónomas que accedieron a la autonomía por la vía del art. 143, el segundo de los compromisos se tradujo en la reforma de todos los Estatutos de estas Comunidades Autónomas, más el valenciano (Leyes Orgánicas 1 a 12, de 24 de marzo de 1994), conforme a la homogeneidad que aseguraba aquella Ley. En el caso de Castilla y León, la reforma del Estatuto determinó una nueva redacción de sus arts. 24 y 26 a 29, incrementando significativamente el nivel de competencias de la Comunidad, entre ellas, las de desarrollo legislativo y ejecución sobre educación con un nuevo art. 27 bis, que no serían transferidas -sobre todo la no universitaria- hasta años posteriores.

Corolario de la anhelada equiparación competencial con las restantes Comunidades Autónomas, la reforma de 1999, coincidiendo con otro ciclo de reformas estatutarias iniciado en 1996 para las Comunidades de régimen común, vino a complementar la primera a través de una mejora en el marco competencial e institucional de la Comunidad. La Ley Orgánica 4/1999, de 8 de enero, en efecto, además de ampliar nuevamente el nivel competencial de Castilla y León, reconociendo -entre otras- la gestión sanitaria con arreglo a las bases y la coordinación estatal (no traspasada efectivamente hasta el 2002), supuso, junto a ciertas innovaciones político-institucionales, la creación o inclusión en el Estatuto de nuevas instituciones de autogobierno, como el Consejo Económico y Social, el Procurador del Común, el Consejo Consultivo y el Consejo de Cuentas.

Finalmente, a pesar de las altas cotas de descentralización y virtual equiparación territorial alcanzadas en estos momentos del proceso, un nuevo impulso a la construcción autonómica se hizo paso con ocasión de la iniciativa de reforma de algunos Estatutos aprobados por la vía privilegiada del art. 151 (Ley Orgánica 6/2006, de 19 de julio, de reforma del Estatuto de Autonomía de Cataluña; Ley Orgánica 2/2007, de 19 de marzo, de reforma del Estatuto de Autonomía de Andalucía), entre las que también se encontraba la "Propuesta de Estatuto Político de la Comunidad de Euskadi", rechazada por el Congreso el 1 de febrero de 2005. Una nueva etapa, formalizada inicialmente con la reforma del Estatuto de Autonomía de la Comunidad Valenciana (Ley Orgánica 1/2006, de 10 de abril), de la que han acabado participando otras Comunidades, como Castilla y León, mediante su tercera reforma estatutaria aprobada por Ley Orgánica 14/2007, de 30 de noviembre.

En este contexto de reformas generalizadas, el modelo general resultante, con claros síntomas federales y confederales, fruto aún de un principio dispositivo incapaz de embridar las inercias y mimetismos del proceso, no ha dejado indiferente a la doctrina (Sosa Wagner, Muñoz Machado)..$^{10}$ Los esperados juicios de constitucionali-

10 Sosa Wagner, F.: Estudio introductorio: El Estado se desarma a Darnstädt, T.: La trampa del consenso, Trotta, Madrid, 2005; y Prólogo para los españoles a Vandelli, L.: Trastornos de las instituciones políti- 
dad de los Estatutos, a partir ya de la reciente STC 31/2010, de 28 de junio, sobre la reforma del Estatuto de Autonomía de Cataluña, y el conocido debate sobre la reforma constitucional a modo de posible cierre del sistema (Argullol Murgadas, Barnés Vázquez), ${ }^{11}$ completan a estas alturas del proceso autonómico el horizonte territorial.

\section{STATU QUO DEL PROCESO DESCENTRALIZADOR DESDE UNA PERSPECTIVA INSTITUCIONAL}

“Tan oportuna como necesaria" son los calificativos que el Preámbulo del nuevo Estatuto de Autonomía de Castilla y León atribuye a su última reforma de 2007, teniendo en cuenta los actuales retos y realidades cambiantes en el orden internacional e interno. Se trata de "disponer de un Estatuto -señala- que, dentro del marco constitucional, alcance su más alto nivel”. De ahí que la reforma se traduzca en el reconocimiento para su mejor protección de "derechos sociales de los ciudadanos de Castilla y León”, en nuevas “disposiciones que profundizan y perfeccionan los instrumentos de autogobierno" y mejoran el "funcionamiento institucional”, y "nuevas competencias" sin perjuicio de "espacios competenciales abiertos al futuro".

Afirmaciones todas ellas que encuentran su debida traslación en un Estatuto que ciertamente puede considerarse renovado en profundidad merced a esta tercera modificación, en el contexto ya señalado de las importantes innovaciones estatutarias concernientes por vez primera a Comunidades del art. 151. No en vano, a partir de la completa redacción del articulado, aun tratándose formalmente de una Ley de Reforma del primitivo Estatuto, aprobado por Ley Orgánica 4/1983, de 25 de febrero (a diferencia de Cataluña, cuya Ley Orgánica 6/2006, de 19 de julio, ha derogado expresamente la originaria Ley Orgánica 4/1979, de 18 de diciembre), se opera una nueva estructuración y considerable ampliación del mismo, pasando de IV a VII Títulos, y de 55 a 91 artículos.

Junto a la asunción de competencias inéditas, como las relativas a las aguas de la Cuencia del Duero (art. 75) ${ }^{12}$ o a un futuro Cuerpo de Policía de Castilla y León (art. 72.3), y la previsión de instituciones noveles de la importancia del Consejo de Justicia de Castilla y León (art. 42) o de una suerte de Agencia Tributaria propia (art. 86.3), en los términos precisados infra, otras primicias forman parte del legado de la Ley Orgánica 14/2007, de 30 de noviembre, entre ellas, el reconocimiento de la propia identi-

cas, Trotta, Madrid, 2007; Sosa Wagner, F. y Sosa Mayor, I.: El Estado fragmentado. Modelo austro-húngaro y brote de naciones en España, Prólogo de Joaquín Leguina, Trotta, Madrid, 2006; Muñoz Machado, S.: El problema de la vertebración del Estado en España (del siglo XVIII al XXI), lustel, Madrid, 2006; y Derecho Público de las Comunidades Autónomas, 2 vols., lustel, Madrid, 2007.

11 Argullol Murgadas, E.: “La reforma estatutaria: una primera aproximación”, Revista de Administración Pública, núm. 174, 2007; Barnés Vázquez, J.: “Un Estatuto de Autonomía y una Constitución del siglo XXI”, Revista de Administración Pública, núm. 173, 2007, págs. 293 a 315.

12 Caro-Patón Carmona, I.: “Aguas y Cuenca del Duero”, en VV.AA. (Dir.: Sáez Hidalgo, I.): Derecho Público de Castilla y León, Lex Nova, Valladolid, 2008, págs. 1.057 a 1.087. 
dad histórica y cultural de la Comunidad, la declaración de derechos de los castellanos y leoneses, o su escenario de relaciones internas y externas desde una especial vocación europea y proyección exterior.

Pero una vez reconocido el alcance de la reforma que nos ocupa, no puede dejarse de poner de manifiesto a renglón seguido que la misma ha incidido en realidad sobre un marco político y jurídico ya altamente descentralizado. Los umbrales de descentralización alcanzados en virtud de las anteriores fases del proceso, tanto desde la óptica del Estado en su conjunto como de la Comunidad castellana y leonesa, se convierten sin duda en el elemento de partida inexcusable para cualquier análisis de aquélla. De forma que no tendrá el mismo valor un estudio aséptico de los últimos acontecimientos en política territorial que un examen debidamente contextualizado a partir del incesante avance del fenómeno.

Hay que recordar en este sentido que, fruto también del principio dispositivo en la vertiente institucional, todas las Comunidades Autónomas sin excepción recogieron en sus Estatutos un modelo de organización idéntico al previsto en el art. 152.1 de la Constitución, a pesar de que el mismo sólo estaba previsto imperativamente para las Comunidades del art. 151. En virtud del art. 147.2.c), que fijaba entre las determinaciones estatutarias la denominación, organización y sede de las instituciones autonómicas, todos los Estatutos, incluidos los de las Ciudades Autónomas de Ceuta y Melilla, si bien en este caso con importantes modulaciones, adoptaron una organización institucional común basada en una Asamblea legislativa o Parlamento autonómico, un Consejo de Gobierno con su Presidente, además de un Tribunal Superior de Justicia. La extensión de la potestad legislativa a las Comunidades Autónomas de régimen común supuso así la primera decisión clave hacia la generalización de un modelo avanzado de descentralización política, llamado a fortalecerse y acrecentarse sin un final predeterminado.

En el curso de este proceso, tal como se vio, las Comunidades Autónomas que accedieron a la autonomía por la vía lenta del art. 143 no renunciaron tampoco a su igualación competencial con el resto de Comunidades de autonomía plena, en los términos del art. 148.2. Superado el plazo constitucional, y desde el consenso de las grandes formaciones políticas, dichos Estatutos fueron reformados a fin de lograr la equiparación virtual entre todas las Comunidades Autónomas, si se exceptúan las singularidades lingüísticas, insulares o de financiación. Precisamente la enorme complejidad de nuestro sistema de financiación autonómica, con un régimen foral y otro común, y dentro de éste un régimen especial para Canarias -donde se reconocen distintos grados de participación normativa y de gestión en los tributos, corregidos por determinados parámetros de equidad redistributiva-, no supone sino otra manifestación de la singularidad federal con la que contaba nuestro modelo antes de la última vuelta de tuerca territorial. El importante elenco de competencias y servicios atribuidos a responsabilidad autonómica no tardaría en proyectarse sobre las estadísticas de gasto público o porcentajes de empleados públicos al servicio de las Comunidades Autónomas, acaparando este nivel territorial por vez primera la mitad del con88 junto de estos últimos, por delante de las Corporaciones locales y del propio Estado. 
Periplo del que naturalmente no ha sido ajeno el territorio de Castilla y León, comprometido en todo momento con el fortalecimiento y profundización de su proyecto histórico. Las primeras reformas de la Norma institucional básica de la Comunidad en virtud de las Leyes Orgánicas 11/1994, de 24 de marzo y 4/1999, de 8 de enero, no sólo supondrían la ansiada equiparación competencial con el resto de Autonomías, a partir sobre todo de las transferencias en materia de educación y sanidad, sino además un incremento significativo en el nivel de autogobierno con notables mejoras de la organización y funcionamiento institucional.

\section{ENTRAMADO ORGANIZATIVO DE CASTILLA Y LEÓN CONFORME A LA LEY ORGÁNICA 14/2007, DE 30 DE NOVIEMBRE, DE REFORMA DE SU ESTATUTO DE AUTONOMÍA}

\subsection{INSTITUCIONES BÁSICAS DE AUTOGOBIERNO}

\subsubsection{Las Cortes de Castilla y León}

El vigente art. 19.1 del Estatuto de Autonomía establece que "las instituciones básicas de la Comunidad de Castilla y León son: las Cortes de Castilla y León, el Presidente de la Junta de Castilla y León, y la Junta de Castilla y León”. Una previsión, presente desde la primigenia redacción del Estatuto, incardinada y desarrollada por el Título II bajo el rótulo "Instituciones de autogobierno de la Comunidad", tras el Título Preliminar y Título I, dedicado en la actualidad a los "Derechos y principios rectores".

La institución parlamentaria, bajo la denominación formal de "Cortes de Castilla y León” y regulada en el Capítulo I de este Título II, se erige en el primer y fundamental pilar de una estructura organizativa que, como el resto de Comunidades de régimen común, ha seguido el mismo esquema del art. 152.1 de la Constitución; a saber: una Asamblea legislativa o Parlamento autonómico, elegida por sufragio universal; un Consejo de Gobierno con funciones ejecutivas y administrativas, bajo la dirección de un Presidente, designado por aquélla mediante una relación de confianza propia de los regímenes parlamentarios; y un Tribunal Superior de Justicia como culminación de la organización judicial en el ámbito de la Comunidad, a la que se dedica el Capítulo V. En la decisión política que llevó a la generalización y homogeneización institucional de todas las Comunidades Autónomas en uso del principio dispositivo se encuentra el germen de este modelo autonómico común, fiel a su vez al patrón estatal, que cuenta no obstante con algunas especialidades organizativas.

Conforme al mencionado Capítulo I (“Las Cortes de Castilla y León”) y también Capítulo IV ("Relaciones entre las Cortes de Castilla y León y la Junta de Castilla y León y su Presidente”) del Título II del Estatuto, y el propio Reglamento interno y Estatuto del Personal de las Cortes de Castilla y León (art. 23.4 del Estatuto), el análisis de esta institución exige reparar al menos en los siguientes apartados, con un régimen jurídico coincidente en buena medida al del resto de Parlamentos autonómicos: carácter y 
elección; organización, funcionamiento y estatuto de sus miembros; y atribuciones o funciones. Atribuciones entre las que se encontrarán las propias de cualquier Cámara legislativa: el control de la acción política y de gobierno y la potestad legislativa, localizándose en esta última precisamente una de las novedades de la reforma estatutaria de 2007, como es la posibilidad de que la Junta pueda adoptar Decretos-Leyes, que deberán someterse en el plazo improrrogable de treinta días a las Cortes de Castilla y León para su convalidación o derogación, sin perjuicio de su posible tramitación por vía de urgencia como proyectos de Ley.

Las Asambleas legislativas o Parlamentos autonómicos, en efecto, constituyen los órganos de representación política de los ciudadanos que integran la población autonómica, estando constituidos todos ellos por una sola Cámara. ${ }^{13}$ Sus miembros, que en las Cortes de Castilla y León reciben la denominación tradicional de Procuradores, son elegidos para un mandato de cuatro años -salvo disolución anticipada de la Cámara acordada por el Presidente- en virtud de sufragio universal, libre, igual, directo y secreto, mediante un sistema de representación proporcional que asegure además la representación de las diversas zonas del territorio, según dispone el art. 152.1 de la Constitución y 21 del Estatuto de Castilla y León. Con arreglo a este último precepto, en la Comunidad castellana y leonesa la circunscripción electoral es la provincia, asignándose a cada una un número mínimo de tres Procuradores y uno más por cada 45.000 habitantes o fracción superior a 22.500 (véase la Ley 3/1987, de 30 de marzo, Electoral de Castilla y León).

El estatuto de los Procuradores -los cuales, según el art. 22.1, "representan a la totalidad del pueblo de Castilla y León y no están ligados por mandato imperativo alguno"- viene prefigurado en el apartado 2 del mismo precepto estatutario, donde se reconoce, por un lado, la inviolabilidad por sus opiniones o votos, y, por otro, el privilegio de no poder ser retenidos ni detenidos durante su mandato, salvo en caso de flagrante delito, gozando en todo caso de un fuero especial ante el Tribunal Superior de Justicia de Castilla y León o Tribunal Supremo, según que la responsabilidad penal resulte exigible dentro o fuera del territorio autonómico (en parecidos términos se pronuncia el art. 29 respecto a las prerrogativas del Presidente y demás miembros de la Junta). Por el contrario, y a diferencia de las Cortes Generales, estos parlamentarios autonómicos no gozan de la inmunidad por la que se exigiría suplicatorio o autorización del Parlamento para hacer posibles sus procesamientos. El art. 23, por lo demás, se refiere al funcionamiento y órganos de la Cámara, aspectos debidamente desarrollados por su Reglamento interno.

En cuanto a las atribuciones de las Cortes Regionales, a las ya mencionadas de la potestad legislativa (significativamente la aprobación de Presupuestos y el establecimiento de tributos) y el control del ejecutivo autonómico, hay que sumar otras numerosas competencias recogidas en el art. 24 y con carácter general el texto constitucional, como la designación de los Senadores representantes de la Comunidad (art. 69.5

13 Por todos, Embid Irujo, A.: Los Parlamentos territoriales, Tecnos, Madrid, 1987. 
de la Constitución, y Ley autonómica $7 / 1987$, de 8 de mayo, modificada por la Ley 1/2000, de 3 de marzo), la iniciativa legislativa a nivel nacional solicitando del Gobierno central la adopción de un proyecto de Ley o remitiendo a la Mesa del Congreso de los Diputados una proposición de Ley (art. 87.2 de la Constitución), o la misma legitimación para interponer recursos de inconstitucionalidad [art. 162.1.a) de la Constitución]. Finalmente, por su trascendencia, no puede dejarse de mencionar, en los términos y límites prescritos en el art. 25 del Estatuto, los supuestos de delegación legislativa a favor de la Junta, así como el posible dictado por ésta de Decretos-Leyes en casos de extraordinaria y urgente necesidad (reforma de 2007); junto, por otro lado, el explícito reconocimiento estatutario desde la reforma de 1999 de la cuestión de confianza (regulada ya por la Ley 1/1996, de 27 de marzo, junto a la facultad del Presidente de la Junta de disolución de las Cortes de Castilla y León) y moción de censura en cuanto especiales mecanismos de control parlamentario que exigen para su aprobación, respectivamente, mayoría simple (art. 35) y mayoría absoluta (art. 36) de los Procuradores.

\subsubsection{La Junta de Castilla y León y su Presidente}

Siguiendo una vez más la estructura institucional del art. 152.1 de la Constitución, concerniente a las Comunidades Autónomas de primer grado pero asumida homogéneamente por todas las Autonomías, el Título II del Estatuto de Castilla y León alberga los aspectos fundamentales de las otras dos instituciones básicas de autogobierno de la Comunidad, como son la Junta de Castilla y León (Capítulo III) y su Presidente (Capítulo II). ${ }^{14}$ Dos máximos órganos ejecutivos, colegiado y unipersonal, cabezas visibles del organigrama del aparato administrativo autonómico, regulados junto al resto de órganos gubernativos por la Ley 3/2001, de 3 de julio, del Gobierno y de la Administración de la Comunidad de Castilla y León.

Sistema institucional que en sus relaciones recíprocas obedece al modelo de organización propio de los sistemas parlamentarios, a partir de las siguientes premisas: el Presidente de la Junta de Castilla y León es elegido por las Cortes de Castilla y León de entre sus miembros y nombrado por el Rey (art. 26 del Estatuto), debiendo gozar en todo momento de la confianza de la Cámara para mantenerse en el cargo (cuestión de confianza y moción de censura); el Presidente, a su vez, es el que nombra y separa libremente a los demás miembros de la Junta, comunicándolo a las Cortes, estando compuesta, además de por el Presidente que la dirige, por los Vicepresidentes, en su caso, y los Consejeros (arts. 28 del Estatuto y 15 de la Ley 3/2001, de 3 de julio); siendo todos los miembros de la Junta políticamente responsables ante las Cortes, que ejercerá el control sobre los mismos a través de las correspondientes

14 Albertos Carazo, M.: La figura del Presidente de la Comunidad Autónoma en el sistema constitucional español, Thomson-Aranzadi, Navarra, 2006; Matía Portilla, F. J.: “El Presidente de la Junta”, en VV. AA. (Dir.: Sáez Hidalgo, I.): Derecho Público de Castilla y León, Lex Nova, Valladolid, 2008, págs. 363 a 419; Martínez López-Muñiz, J. L.: “La Junta”, en VV.AA. (Dir.: Sáez Hidalgo, I.): Derecho Público de Castilla y León, Lex Nova, Valladolid, 2008, págs. 421 a 446. 
técnicas parlamentarias previstas en el Reglamento de la Cámara (arts. 34 del Estatuto y 21 de la Ley 3/2001, de 3 de julio).

Entre sus funciones, junto a la presidencia, dirección y coordinación de la Junta, corresponde al Presidente la suprema representación de la Comunidad y la ordinaria del Estado en aquélla -esto es, en defecto de otras máximas autoridades estatales-, a través de las atribuciones institucionales, ejecutivas y reglamentarias que desglosan los arts. 27 del Estatuto, y 6 y 7 de la Ley 3/2001, de 3 de julio. La Junta, por su parte, en cuanto órgano de gobierno y administración de la Comunidad, ejerce la función ejecutiva y la potestad reglamentaria de acuerdo con el ordenamiento jurídico, además de la iniciativa legislativa autonómica, y la potestad para dictar Decretos Legislativos y Decretos-Leyes autonómicos en los términos referidos. Asimismo, a tenor de la Constitución y la Ley Orgánica del Tribunal Constitucional, la Junta goza de legitimación para interponer recursos de inconstitucionalidad o plantear conflictos de competencia con el Estado u otras Comunidades Autónomas. Atribuciones, reconocidas a lo largo del Estatuto y el art. 16 de la Ley 3/2001, para cuyo ejercicio la Junta puede actuar en Consejo de Gobierno o Comisiones Delegadas.

Los Vicepresidentes y Consejeros, en cuanto miembros también de la Junta, ejercen las funciones que tienen atribuidas normativamente (arts. 23 y 26 de la Ley 3/2001), y las que el Presidente o la Junta les encomienden o deleguen. Los primeros, potestativos y de naturaleza esencialmente vicaria, pueden asumir la titularidad de una Consejería, en cuyo caso ostentarán la condición añadida de Consejeros. Según el art. 36 de la Ley 3/2001, "la Administración General de la Comunidad se organiza funcionalmente en departamentos, bajo la denominación de Consejerías", correspondiendo a cada una de ellas "el desarrollo de uno o varios sectores funcionalmente homogéneos de actividad administrativa", donde el Consejero ejerce la representación, acción de gobierno, dirección administrativa y potestad reglamentaria.

Al amparo del art. 45.1 de la Ley 3/2001, según el cual "la creación, modificación o supresión de Consejerías y Viceconsejerías se llevará a cabo por Decreto del Presidente de la Junta de Castilla y León [... ]", dando cuenta a las Cortes de Castilla y León cuando se trate de aquéllas, la última reestructuración de las mismas se ha realizado en virtud del Decreto 2/2007, de 2 de julio, estableciendo su art. 1 las siguientes Consejerías: Presidencia, Administración Autonómica, Interior y Justicia, Hacienda, Economía y Empleo, Fomento, Agricultura y Ganadería, Medio Ambiente, Sanidad, Familia e Igualdad de Oportunidades, Educación, y Cultura y Turismo.

\subsection{INSTITUCIONES PROPIAS Y DEMÁS ÓRGANOS AUTONÓMICOS}

\subsubsection{El Consejo Económico y Social}

Junto a la previsión de las instituciones básicas de la Comunidad en el art. 19.1 del

92 Estatuto de Autonomía, la reforma de 2007 especifica que "son instituciones propias 
de la Comunidad de Castilla y León el Consejo Económico y Social, el Procurador del Común, el Consejo Consultivo, el Consejo de Cuentas", aparte de "las que determinen el presente Estatuto o las leyes aprobadas por las Cortes de Castilla y León”. Instituciones que, sin embargo, ya habían sido previstas o incluidas en el texto estatutario a raíz de la reforma de 1999, contando desde entonces con alguna disposición específica diseminada a lo largo del Estatuto.

El Consejo Económico y Social de Castilla y León, en concreto, fue creado en virtud de la Ley 13/1990, de 28 de noviembre (modificada por las Leyes 8/1996, de 27 de diciembre y 9/2004, de 28 de diciembre), siendo aprobado su Reglamento de organización y funcionamiento por Decreto 2/1992, de 16 de enero. Regulación a la que se remite el actual art. 81 del Estatuto, dentro del Título VI dedicado a la Economía y Hacienda de la Comunidad.

Entre la diversidad de órganos o entes con funciones consultivas en todos los niveles del sector público autonómico, el Consejo Económico y Social proyecta su carácter consultivo y asesor sobre la vertiente socioeconómica de Castilla y León, operando, como su homónimo estatal, de cauce estable y permanente para el asesoramiento y diálogo tanto de las organizaciones empresariales y sindicales entre sí como de éstas con la Administración regional. Formalmente se configura como un órgano colegiado de carácter consultivo pero dotado de personalidad jurídica propia e independiente respecto de los órganos de la Comunidad, con funciones de consulta, estudio y colaboración en materias socioeconómicas en el ámbito autonómico.

Su composición con treinta y seis miembros representativos de los distintos intereses económicos y sociales, atribuciones (informe previo y preceptivo sobre los proyectos de Ley y Decreto relacionados con la política socioeconómica, a excepción de los proyectos de Ley de Presupuestos Generales de la Comunidad, que deben ser no obstante remitidos; informe anual sobre la situación socioeconómica de la Región; recomendaciones, propuestas, estudios, y demás dictámenes e informes), y estructura (Pleno, Comisión Permanente y Comisiones de Trabajo) se adecuan a la naturaleza y objetivos de esta institución autonómica de Derecho público, en cuanto marco privilegiado para la colaboración de las fuerzas sociales en la política social y económica de la Comunidad. ${ }^{15}$

\subsubsection{El Procurador del Común}

Definido por el art. 18 del Estatuto como "el Alto Comisionado de las Cortes de Castilla y León [... ] para la protección y defensa de los derechos constitucionales de

15 VV.AA. (Coord.: Ojeda Avilés, A.): Los Consejos Económicos y Sociales, Trotta, Madrid, 1992; Allué Buiza, A.: “El Consejo Económico y Social”, en VV.AA. (Dir.: Sáez Hidalgo, I.): Derecho Público de Castilla y León, Lex Nova, Valladolid, 2008, págs. 539 a 556. 
los ciudadanos y de los derechos y principios reconocidos en el presente Estatuto frente a la Administración de la Comunidad, la de sus Entes locales y la de los diferentes Organismos que de éstas dependan", el Procurador del Común de Castilla y León se halla regulado por la Ley 2/1994, de 9 de marzo (modificada por la Ley 11/2001, de 22 de noviembre) y su Reglamento de organización y funcionamiento de 21 de marzo de 2003, normativa a la que se remite el citado precepto, en el contexto del Capítulo $\checkmark$ del Título I sobre "Garantías de los derechos y principios estatutarios". A diferencia del anterior art. 14, vinculado al órgano legislativo autonómico, la nueva previsión estatutaria omite la referencia a la tutela del ordenamiento jurídico de la Comunidad y a la defensa del Estatuto, incorporando una alusión a los derechos y principios regionales frente a las distintas Administraciones del territorio autonómico, con el fin seguramente de reencontrar la identidad originaria de esta institución una vez superado el vacío dogmático del Estatuto.

Como el resto de Comisionados autonómicos y el mismo Defensor del Pueblo, que siguen el modelo del Ombudsman sueco, constituye una vía más de control externo de la Administración, ${ }^{16}$ esto es, un órgano designado por las Cortes de Castilla y León para la supervisión de las resoluciones y demás actuaciones administrativas ante su potencial carácter lesivo para los derechos de los ciudadanos (el art. 12 del Estatuto se refiere, en particular, al derecho a una buena Administración). Su nombramiento, para un período de cinco años, precisa mayoría de tres quintas partes de las Cortes Regionales, debiendo presentar a la misma anualmente un informe, cuyo resumen debe ser expuesto en sesión específica del Pleno de la Cámara y en la que podrán intervenir los Grupos Parlamentarios, amén de informes extraordinarios por motivos de urgencia o importancia de los hechos que lo motiven. ${ }^{17}$

El Procurador del Común, auxiliado por un Adjunto, actúa con independencia en su misión fiscalizadora, bien de oficio o como consecuencia de las quejas o peticiones que le sean presentadas, ejerciendo sobre las autoridades, organismos y funcionarios de las Administraciones con sede en la Comunidad una verdadera "magistratura de persuasión" en defensa de los derechos y libertades, quienes están obligados a auxiliarle con carácter preferente y urgente en sus investigaciones. Por otra parte, debe cooperar y coordinar sus funciones con las del Defensor del Pueblo y el resto de instituciones afines, pudiendo celebrar a tal fin convenios de colaboración, en el marco de su normativa reguladora y de la Ley estatal 36/1985, de 6 de noviembre, por la que se regulan las relaciones entre dicha institución central y las figuras similares de las Comunidades Autónomas.

16 Embid Irujo, A.: El control de la Administración Pública por los Comisionados Parlamentarios Autonómicos, Ministerio de Administración Pública, Madrid, 1991; VV.AA.: El Procurador del Común. De fensor del Pueblo y Comunidades Autónomas, Cortes de Castilla y León y Universidad de Valladolid, 1995; Vera Santos, J. M.: El Defensor del Pueblo en la Constitución y en los Estatutos de Autonomía, CEPC y BOE, Madrid, 2002.

$94 \quad 17 \quad$ Corchete Martín, M. J.: "El Procurador del Común”, en VV. 


\subsubsection{El Consejo Consultivo}

Tras la previsión del Consejo Consultivo de Castilla y León en el antiguo art. 24 del Estatuto a partir de su reforma de 1999, este superior órgano consultivo de la Junta y de la Administración regional fue regulado por la Ley 1/2002, de 9 de abril (mínimamente modificada por la Ley 12/2005, de 27 de diciembre, reguladora del Estatuto de los ex Presidentes de la Comunidad), junto al Decreto 102/2003, de 11 de septiembre, por el que se aprobó su Reglamento Orgánico, estando hoy prevista su existencia y regulación en el art. 33 del Estatuto.

A partir de la experiencia históricamente contrastada del Consejo de Estado y otros Consejos Consultivos territoriales, y la doctrina del Tribunal Constitucional sobre las instituciones consultivas (en particular, STC 204/1992, de 26 de noviembre), ha sido configurado como el máximo órgano consultivo de la Comunidad de Castilla y León, gozando de autonomía orgánica y funcional al objeto de garantizar la objetividad e independencia en su alta función consultiva. ${ }^{18}$ Según la citada normativa, el Consejo debe elevar anualmente al Presidente de la Junta de Castilla y León una memoria en la que refleje no sólo el resultado de su actividad consultiva sino también las correspondientes observaciones y recomendaciones para un mejor funcionamiento de las Administraciones públicas de la Comunidad.

Junto a su composición colegiada (con Consejeros Electivos y Natos, además del Presidente y el Secretario General) y régimen de funcionamiento (en Pleno y en Secciones), especialmente relevantes son las reglas competenciales que concretan los supuestos en que debe ser consultado preceptivamente por la Administración, el régimen de las consultas facultativas, así como de las consultas de las Corporaciones locales a través de la Consejería competente en materia de Administración territorial. La ordenación de los distintos aspectos de los dictámenes, en cuanto instrumentos esencialmente jurídicos en que se materializa la función consultiva, completan, junto a otras previsiones de índole organizativa y procedimental, dicha regulación.

\subsubsection{El Consejo de Cuentas}

Contemplado originariamente en el art. 51 del Estatuto, conforme a su reforma de 1999, el actual art. 90 se refiere con idéntica redacción a esta institución, una vez

18 Véanse García Trevijano-Garnica, E.: “La función consultiva de las Administraciones públicas, con especial referencia al Consejo de Estado y las Comunidades Autónomas", Revista de Administración Pública, núm. 133, 1994; Font i Llovet, T.: “Función consultiva y Estado autonómico”, Revista de Administración Pública, núm. 138, 1995; Ruiz Miguel, C.: Consejo de Estado y Consejos Consultivos autonómicos, Dykinson, Madrid, 1995; VV.AA.: El Consejo de Estado, Documentación Administrativa, núms. 244-245, 1996; VV.AA. (Coord.: Biglino Campos, P.): Consejos Consultivos y Comunidades Autónomas: la Institución en CastiIla y León, Cortes de Castilla y León y Universidad de Valladolid, Valladolid, 2003; y Salgueiro Cortiñas, M. ${ }^{\text {J J.: }}$ “El Consejo Consultivo”, en VV.AA. (Dir.: Sáez Hidalgo, I.): Derecho Público de Castilla y León, Lex Nova, Valladolid, 2008, págs. 557 a 582. 
aprobada su normativa reguladora -a la cual se remite el mismo-integrada por la Ley 2/2002, de 9 de abril, del Consejo de Cuentas de Castilla y León, y su Reglamento de organización y funcionamiento de 17 de marzo de 2004 (amén de otras normas en liza, como la Ley $2 / 2006$, de 3 de mayo, de la Hacienda y el Sector Público de Castilla y León).

A tenor de dicha redacción, "el Consejo de Cuentas, dependiente de las Cortes de Castilla y León, realizará las funciones de fiscalización externa de la gestión económica, financiera y contable del sector público de la Comunidad Autónoma y demás entes públicos de Castilla y León, sin perjuicio de las competencias que corresponden al Tribunal de Cuentas de acuerdo con la Constitución”. Auxiliar pues de las Cortes Regionales, este nuevo órgano de control externo del sector público autonómico, en su vertiente económica, financiera y contable, ha de desempeñar su labor en concurso con la Intervención General de la Administración de la Comunidad como instancia de control interno, el Tribunal de Cuentas central en cuanto supremo órgano censor de las cuentas y gestión económica del sector público en su conjunto, incluido el autonómico [art. 153.d) de la Constitución], y el propio Tribunal de Cuentas Europeo, en la medida en que dicho sector es receptor también de fondos comunitarios. ${ }^{19}$ Respecto a la necesidad de coordinación con el Tribunal de Cuentas, que alcanza incluso la posible participación en su función exclusiva de enjuiciamiento contable, ${ }^{20}$ ténganse en cuenta los arts. 17 y 29 de la Ley estatal 7/1988, de 5 de abril, de Funcionamiento del Tribunal de Cuentas.

Una institución autonómica de fiscalización externa, también con funciones consultivas y de asesoramiento al Parlamento Regional, estructurada en Pleno, Presidente, Consejeros de Cuentas y Secretaría General, cuyos cinco Consejeros de Cuentas deben ser elegidos mediante mayoría cualificada de tres quintos de la Cámara en primera votación o mayoría absoluta en segunda votación, para un período de seis años.

Su función de control, desarrollada conforme a un Plan anual de fiscalizaciones y con plena independencia de los entes auditados (administración de las Cortes de Castilla y León y de las Instituciones dependientes de ellas; Administración de la Comunidad Autónoma, junto a sus Organismos autónomos, Entes públicos y empresas públicas; Entidades locales del ámbito territorial de la Comunidad, con sus Organismos autónomos, Entes públicos y empresas públicas; y Universidades públicas de Castilla y León, y organismos y sociedades dependientes de ellas), se traduce en la emisión de

19 Vera Santos, J. M.: El Tribunal de Cuentas y los órganos de control externo de las Comunidades Autónomas, CEPC, Madrid, 2001; VV.AA.: Estudios sobre el control externo autonómico, Civitas, Madrid, 2002; Vallès y Vives, F.: El control externo del gasto público: configuración y garantía institucional, CEPC, Madrid, 2003; Durán Alba, J. F.: “El Consejo de Cuentas”, en VV.AA. (Dir.: Sáez Hidalgo, I.): Derecho Público de Castilla y León, Lex Nova, Valladolid, 2008, págs. 583 a 603.

20 Velgado del Rincón, L. E.: “La función de enjuiciamiento contable de los órganos de control externo de las Comunidades Autónomas”, Revista Vasca de Administración Pública, núm. 55, 1999, págs. 103-132. 
informes de fiscalización, recogidos ulteriormente en una memoria que el Consejo debe remitir cada ejercicio a las Cortes de Castilla y León para su tramitación y debate parlamentario.

\subsubsection{Otras instituciones estatutarias}

La última reforma de 2007 del Estatuto ha querido profundizar en la estructura institucional autonómica, incorporando por vez primera en su texto determinadas instituciones que, siguiendo la estela de otras Autonomías, pueden venir a enriquecer cualitativamente el plantel organizativo de la Región por su importante peso para el nivel de autogobierno.

Entre esas nuevas instituciones, dispares y heterogéneas, y anudadas en su creación a la potestad legislativa de las Cortes Regionales, se encuentran el Consejo de Justicia de Castilla y León, una suerte de Agencia Tributaria propia, y a mayor distancia, la Agencia de Protección de Datos de la Comunidad de Castilla y León.

Si en el ámbito del Poder Judicial en la Región el art. 42 del Estatuto reconoce que "mediante Ley de las Cortes de Castilla y León se podrá crear el Consejo de Justicia de Castilla y León y establecer su estructura, composición y funciones dentro del ámbito de competencias de la Comunidad y de acuerdo con lo dispuesto en la legislación estatal", en sede de Hacienda autonómica el art. 86.3 prevé de forma más ambigua que "se podrá crear por Ley de Cortes un organismo con personalidad jurídica propia para la gestión, recaudación, liquidación, inspección y revisión de los tributos propios y cedidos". Por su parte, el art. 12.d), a propósito del reconocimiento autonómico del derecho a la protección de los datos personales, contempla también ope legis una posible Agencia de Protección de Datos de la Comunidad, análoga a las que vienen operando en otras Autonomías, para la gestión de aquellos ficheros “dependientes de la Administración autonómica", debiéndose entender por tales -conforme al deslinde competencial establecido en la Ley Orgánica 15/1999, de 13 de diciembre, de Protección de Datos de Carácter Personal, y corroborado por la STC 290/2000, de 30 de noviembre- los ficheros creados o gestionados por ella, así como aquellos pertenecientes a los distintos Entes locales de su ámbito territorial. ${ }^{21}$

21 Cfr. Martínez Martínez, C.: “La experiencia práctica de la Agencia de Protección de Datos de la Comunidad de Madrid para la protección de datos de carácter público", en AAVV (Coord.: Davara Rodríguez, M. A.): Encuentros sobre Informática y Derecho (2000-2001), Universidad Pontificia Comillas, Aranzadi, Pamplona, 2001, págs. 61 a 67; Fernández Salmerón, M.: La protección de los datos personales en las Administraciones públicas, Prólogo de Antonio Troncoso Reigada, Thomson-Civitas, Madrid, 2003; Troncoso Reigada, A.: "La contribución de las Agencias Autonómicas al derecho fundamental a la protección de datos", en AAVV (Coords.: Fernández Salmerón, M.; Sierra Rodríguez, J. y Valero Torrijos, J.): Nuevos retos en el horizonte de las Administraciones públicas, Universidad de Murcia, 2003, págs. 59 a 77; Bacaria Martrus, J.: "La Agencia Catalana de Protección de Datos (algunos aspectos comparativos con la Agencia de Protección de Datos de la Comunidad de Madrid). La cuestión de las competencias autonómicas sobre ficheros de titularidad privada en la Ley catalana", en AAVV (Coord.: Davara Rodríguez, M. A.): Encuentros sobre 
Por último, y en el marco más modesto pero no menos importante de las relaciones institucionales de la Comunidad, el actual Estatuto vuelve a introducir nuevos órganos de colaboración o proyección exterior, como la Comisión de Cooperación entre la Comunidad de Castilla y León y el Estado (art. 59 del Estatuto, en el contexto de las Comisiones Bilaterales de Cooperación del art. 5 de la Ley 30/1992, de 26 de noviembre, de Régimen Jurídico de las Administraciones Públicas y del Procedimiento Administrativo Común, de composición bilateral y ámbito general), el Consejo de Cooperación Local de Castilla y León (principal manifestación institucional de la cooperación interadministrativa entre la Comunidad Autónoma y las Corporaciones locales de Castilla y León, fruto del Acuerdo de Pacto Local de Castilla y León o segundo proceso de descentralización impulsado en la Región desde el año 2005, y que deberá regular la Ley autonómica de Régimen Local, como señala el art. 51 del Estatuto), ${ }^{22}$ o la misma Delegación Permanente de la Comunidad ante la Union Europea que contempla el art. 64 del Estatuto a fin de mantener relaciones de colaboración con las instituciones europeas y de ejercer funciones de información y de promoción y defensa de los intereses regionales, junto a otras vías de presencia institucional en Europa y en el exterior. ${ }^{23}$

\subsubsection{Administración de la Comunidad}

El elenco organizativo de Castilla y León se cierra con los diferentes órganos centrales y periféricos que, subordinados a los órganos superiores ya analizados de la Junta de Castilla y León, Presidencia, Vicepresidencias, en su caso, y Consejerías, conforman la llamada Administración General de la Comunidad, aparte de la Administración Institucional autonómica y otras personificaciones privadas del sector público de la Región.

A los órganos y servicios de la Administración autonómica, y su correspondiente organización burocrática sometida hoy desde un mayor margen de autonomía al Estatuto Básico del Empleado Público de 12 de abril de 2007 (Quintana López),, ${ }^{24}$ se re-

Informática y Derecho (2002-2003), Universidad Pontificia Comillas, Madrid, 2003, págs. 47 a 56; Guichot, E.: Datos personales y Administración pública, Prólogo de Javier Barnés, Thomson-Civitas, Madrid, 2005; Ballesteros Moffa, L. A.: La privacidad electrónica, Prólogo de José Luis Piñar Mañas, Tirant Lo Blanch y Agencia Española de Protección de Datos, Valencia, 2006, págs. 99 y sigs; Fuentetaja Pastor, J. y Medina González, S.: La protección de datos en la Administración local, lustel, Madrid, 2008.

22 Ballesteros Moffa, L. A., "La cooperación institucional en el Acuerdo de Pacto Local de Castilla y León”, en VV.AA. (Coord.: Sosa Wagner, F.): Pacto local, Revista Jurídica de Castilla y León, núm. extraordinario, 2006, págs. 97 a 125.

23 Pueden consultarse al respecto los trabajos de Conde Martínez, C.: La acción exterior de las Comunidades Autónomas, Madrid, 2000; Fernández de Casadevante Romaní, C.: La acción exterior de las Comunidades Autónomas, balance de una práctica consolidada, Dilex, Madrid, 2001; y Mangas Martín, A.: "Acción exterior de la Comunidad Autónoma”, en VV.AA. (Dir.: Sáez Hidalgo, I.): Derecho Público de Castilla y León, Lex Nova, Valladolid, 2008, págs. 667 a 703.

24 Quintana López, T.: “Función pública”, en VV.AA. (Dir.: Sáez Hidalgo, I.): Derecho Público de Castilla y León, Lex Nova, Valladolid, 2008, págs. 477 a 509. Asimismo, García de Coca, J.A. y Calonge Velázquez, A.: “La Ley de la Función Pública de Castilla y León: clon huérfano", Revista de Estudios de la Administración 
fiere el art. 32 del Estatuto de Autonomía, reconociendo para la misma las potestades y privilegios propios de la Administración del Estado. Previsión que, junto al resto de preceptos estatutarios sobre los órganos de gobierno, y la Ley 3/2001, de 3 de julio, del Gobierno y de la Administración de la Comunidad de Castilla y León, constituyen la piedra angular en el desarrollo de la acción de Gobierno y configuración de la actual estructura administrativa.

Dentro de la organización central, bajo la superior dirección del titular de la Consejería, cada Departamento cuenta con los siguientes órganos directivos centrales: Viceconsejerías, de existencia potestativa (Decreto 3/2007, de 11 de julio, y art. 2 del Decreto 72/2007, de 12 de julio), Secretaría General, y Direcciones Generales, pudiendo estas dos últimas organizarse en Servicios, Secciones y Negociados. Como órgano colegiado de asistencia a la Junta de Castilla y León se encuentra la Comisión de Secretarios Generales, regulada en su composición, funcionamiento y competencias por el Decreto 1/2004, de 8 de enero, modificado por el Decreto 65/2007, de 5 de julio.

Por otra parte, la Administración General de la Comunidad se organiza territorialmente en Delegaciones Territoriales de la Junta de Castilla y León en cada una de las Provincias, como órganos directivos periféricos estructurados, a su vez, en una Secretaría Territorial, Departamentos Territoriales, Servicios Territoriales con carácter excepcional, y Secciones y Negociados. El Delegado Territorial, en cuanto titular de la correspondiente Delegación Territorial, representa a la Junta de Castilla y León y a cada una de las Consejerías en la correspondiente Provincia. Con las funciones específicas de coordinación de la gestión periférica de las competencias de la Administración autonómica y unificación de los criterios de actuación en el ámbito territorial, el Decreto 101/2007, de 18 de octubre, ha creado con carácter permanente la Comisión General de Coordinación Territorial.

Respecto a las entidades de la Administración Institucional, bajo la dependencia de la Administración General a través de su adscripción a la Consejería competente por razón de la materia, pero con personalidad jurídica diferenciada, patrimonio y tesorería propios y autonomía de gestión, estas instituciones obedecen al principio de descentralización funcional conforme a su doble clasificación en Organismos autónomos y Entes públicos de Derecho Privado. Además de por su normativa específica y legislación sectorial, se hallan regulados, junto a las empresas públicas de la Comunidad, por el último Título de la Ley 3/2001, de 3 de julio, del Gobierno y de la Administración, en detrimento de su anterior ubicación en la Ley de Hacienda. ${ }^{25}$

Local y Autonómica, núm. 249, 1991, págs. 121 a 146; Fernández Domínguez, J.J. y Rodríguez Escanciano, S.: Hacia un nuevo régimen jurídico del personal al servicio de las Administraciones públicas, Instituto Andaluz de Administración Pública, Sevilla, 2006; Sánchez Morón, M. (Dir.): Comentarios a la Ley del Estatuto Básico del Empleado Público, Lex Nova, Valladolid, 2007; Parada Vázquez, R.: Derecho del Empleo Público. Ley 7/2007, de 12 de abril, del Estatuto Básico del Empleado Público, Marcial Pons, Madrid, 2007; Gámez Gámez, J.A. y Gámez Gámez, A.: Estatuto Básico del Empleado Público, Instituto Andaluz de Administración Pública, Sevilla, 2007; Palomar Olmeda, A.: El Nuevo Estatuto del Empleado Público, Thomson-Aranzadi, Navarra, 2007.

25 Merino Llorente, E.: “La organización de la Administración. Estructuras administrativas", en VV.AA. (Dir.: Sáez Hidalgo, I.): Derecho Público de Castilla y León, Lex Nova, Valladolid, 200, págs. 451 a 476. 


\section{BIBLIOGRAFÍA}

Aja Fernández, E.: El sistema jurídico de las Comunidades Autónomas, Tecnos, Madrid, 1985.

- El Estado autonómico: federalismo y hechos diferenciales, Alianza Editorial, Madrid, 2003.

Albertos Carazo, M.: La figura del Presidente de la Comunidad Autónoma en el sistema constitucional español, Thomson-Aranzadi, Navarra, 2006.

Álvarez Conde, E.: Reforma constitucional y reformas estatutarias, lustel, Madrid, 2007.

Aragón Reyes, M.: "La organización institucional de las Comunidades Autónomas", Revista Española de Derecho Constitucional, núm. 75, 2007.

Argullol Murgadas, E.: “La reforma estatutaria: una primera aproximación”, Revista de Administración Pública, núm. 174, 2007.

Barnés Vázquez, J.: "Un Estatuto de Autonomía y una Constitución del siglo XXI”, Revista de Administración Pública, núm. 173, 2007.

Embid Irujo, A.: Los Parlamentos territoriales, Tecnos, Madrid, 1987.

- El control de la Administración Pública por los Comisionados Parlamentarios Autonómicos, Ministerio de Administración Pública, Madrid, 1991.

Font i Llovet, T.: “Función consultiva y Estado autonómico”, Revista de Administración Pública, núm. 138, 1995.

Fraga Iribarne, M.: El Estado Autonómico, Madrid, 2009.

García de Enterría, E.: Estudios sobre autonomías territoriales, Madrid, 1985.

García Trevijano-Garnica, E.: "La función consultiva de las Administraciones públicas, con especial referencia al Consejo de Estado y las Comunidades Autónomas", Revista de Administración Pública, núm. 133, 1994.

González Clavero, M., Pelaz López, J.-V. y Pérez López, P., Castilla y León en democracia. Partidos, elecciones y personal político. 1977-2007, Junta de Castilla y León, Valladolid, 2007.

Muñoz Machado, S.: El problema de la vertebración del Estado en España (del siglo XVIII al XXI), lustel, Madrid, 2006.

- Derecho Público de las Comunidades Autónomas, 2 vols., lustel, Madrid, 2007.

Parada Vázquez, R.: Derecho Administrativo II. Organización y empleo público, Marcial Pons, Madrid, 2007.

- “La segunda descentralización: del Estado autonómico al municipal”, Revista de Administración Pública, núm.172, 2007.

Parejo Alfonso, L.: “La organización territorial del Estado ¿Proceso a continuar u obra a culminar?, Justicia Administrativa, núm. 31, 2006.

Quintana López, T.: “La actividad de Castilla y León”, en Informe Comunidades Autónomas 2006 (Dir.: Tornos Mas, J.), Instituto de Derecho Público, Barcelona, 2007.

— “La actividad de Castilla y León”, en Informe Comunidades Autónomas 2007 (Dir.: Tornos Mas, J.), Instituto de Derecho Público, Barcelona, 2008.

- “La actividad de Castilla y León”, en Informe Comunidades Autónomas 2008 (Dir.: Tornos Mas, J.), Instituto de Derecho Público, Barcelona, 2009. 
Sanz Pérez, A. L.: La reforma de los Estatutos de Autonomía, Thomson-Aranzadi, Navarra, 2006.

Seijas Villadangos, E.: Estudio introductorio a Watts, R.: Sistemas federales comparados, Marcial Pons, Madrid, 2006.

Sosa Wagner, F.: Estudio introductorio: El Estado se desarma a Darnstädt, T.: La trampa del consenso, Trotta, Madrid, 2005.

- Prólogo para los españoles a Vandelli, L.: Trastornos de las instituciones políticas, Trotta, Madrid, 2007.

— “Estatutos de autonomía y fragmentación de la Administración. La lealtad federal”, en Federalismo y Constitución. Anales de la Cátedra Francisco Suárez, núm. 42, 2008.

- Juristas en la Segunda República. 1. Los iuspublicistas, Marcial Pons, Madrid, 2009.

Sosa Wagner, F. y Fuertes López, M.: El Estado sin territorio. Cuatro relatos de la España autonómica, Marcial Pons, Madrid, 2011.

Sosa Wagner, F. y Sosa Mayor, I.: El Estado fragmentado. Modelo austro-húngaro y brote de naciones en España, Prólogo de Joaquín Leguina, Trotta, Madrid, 2006.

Vera Santos, J. M.: El Tribunal de Cuentas y los órganos de control externo de las Comunidades Autónomas, CEPC, Madrid, 2001.

VV.AA.: El Procurador del Común. Defensor del Pueblo y Comunidades Autónomas, Cortes de Castilla y León y Universidad de Valladolid, 1995.

VV.AA.: La Reforma de los Estatutos de Autonomía, Revista Jurídica de Castilla y León, 2003.

VV.AA.: (Coord.: Álvarez Conde, E.): El futuro del modelo de Estado, Comunidad de Madrid, 2007.

VV.AA. (Coord.: Bassols Coma, M.): La Administración Pública de las Comunidades Autónomas, INAP, Madrid, 2004.

VV.AA. (Coord.: Biglino Campos, P.): Consejos Consultivos y Comunidades Autónomas: la Institución en Castilla y León, Cortes de Castilla y León y Universidad de Valladolid, Valladolid, 2003.

VV.AA. (Coord.: Blanco Rodríguez, J. A.): Regionalismo y autonomía en Castilla y León, Junta de Castilla y León, Valladolid, 2004.

VV.AA. (Coord.: Espín Templado, E.): La Constitución de 1978 y las Comunidades Autónomas, CEPC, Madrid, 2003.

VV.AA. (Coord.: García Roca, J.): Derecho Público de Castilla y León, Universidad de Valladolid, 1999.

VV.AA. (Coord.: Ojeda Avilés, A.): Los Consejos Económicos y Sociales, Trotta, Madrid, 1992.

VV.AA. (Dir.: Rivero Ysern, E.): Comentarios al Estatuto de Autonomía de la Comunidad Autónoma de Castilla y León, IEAL, Madrid, 1985.

VV.AA. (Dir.: Sáez Hidalgo, I.): Derecho Público de Castilla y León, Lex Nova, Valladolid, 2008.

VV.AA. (Coord.: Sosa Wagner, F.): Pacto local, Revista Jurídica de Castilla y León, núm. extraordinario, 2006. 
